\title{
"Lumbiá": O Deus-menino Erê, de Conceição Evaristo
}

\section{RESUMO}

\section{Leandro Passos}

leandro.passos@ifms.edu.br

Instituto Federal de Educação, Ciência e

Tecnologia de Mato Grosso do Sul, Três

Lagoas, Mato Grosso do Sul, Brasil.

\begin{abstract}
Este artigo analisa o modo como a escritora Conceição Evaristo insere elementos da cultura iorubá e banto atrelados à cultura judaico-cristã, ao gênero e à classe social a partir do conto "Lumbiá", inserido na obra Olhos d'água. Para tanto, serão utilizados os estudos críticos de Martins (2003; 2010) acerca dos termos negritude, negrice e negritice; os de Freitas (2019) e de Oliveira e Almirante (2017) sobre as entidades da umbanda e do candomblé erê; os de Cuti (2010) no que diz respeito à literatura negra, dentre outros teóricos e críticos. Justificase a escrita deste artigo pela proposta do Dossiê "Sociedade e religiões de matriz africana: diálogos", na qual torna-se possível refletir a cultura do terreiro e da divindade criança por meio da linguagem literária. Além disso, o presente texto oportuniza a reflexão da cultura dos povos bantos e iorubás na literatura brasileira contemporânea de forma crítica, pois, por muito tempo, esses grupos foram desqualificados e demonizados. 0 artigo fez parte da pesquisa de estágio pós-doutoral (2018-2020) que investigou a presença dos mitos bantos e iorubás na poética de Conceição Evaristo.
\end{abstract}

PALAVRAS-CHAVE: Conceição Evaristo. Cultura banto-iorubá. Literatura negra. Poética. Subalternidade. 


\section{INTRODUÇÃO}

Conceição Evaristo, mulher, negra, ex-empregada doméstica e babá, nascida na hoje extinta favela do Pendura a Saia em Belo Horizonte, no estado de Minas Gerais, estreou na literatura em 1990, com obras publicadas na série Cadernos Negros. Entretanto, como diz a própria escritora em entrevista ao Portal Geledés ${ }^{1}$, "foi preciso o prêmio Jabuti para comprovar que esta mulher negra aqui não está no espaço literário por intromissão". Vale ressaltar que Evaristo ganhou o prêmio em 2015 na categoria contos e crônicas por sua obra de contos Olhos d'àgua.

A autora é versátil, pois escreve ensaios e artigos literários, cujo campo de pesquisa no Brasil (como tantos outros) é tomado, ainda, pela supremacia de vozes masculinas e brancas. Por outro lado, esse espaço é ocupado também por mulheres, professoras-pesquisadoras que são referências pela qualidade de seus estudos.

Baseando-se nesses aspectos da vida de Evaristo, este artigo propõe-se a refletir sobre a junção da cultura dos iorubás e dos bantos com a cristã, além de suscitar, por meio da narrativa, questões atreladas ao gênero, à raça e à classe. Além disso, justificam-se estas linhas por oportunizar temas que ainda não estão tão presentes nas reflexões curriculares da Educação Infantil à Pós-graduação, mas que tomam espaço significativo e de direito com a implementação da Lei 10.639 de 2003 e 11.645 de 2008.

Para cumprir com o objetivo proposto neste artigo, foram utilizados os posicionamentos da própria escritora sobre a escrita; os de Cuti (2010) acerca da literatura negra; os de Ricardo Piglia (2004) sobre o gênero narrativo conto; os de Regina Dalcastagnè sobre o perfil do escritor brasileiro, os de José Endoença Martins (2003; 2010) sobre o conceito de negritice e os de Ramón Grosfoguel (2008) sobre a necessidade de incluir críticos e culturas não europeias nos debates. Freitas (2019), Oliveira e Almirante auxiliam-nos no entendimento simbólica da entidade criança erê tanto para o culto das religiões de matriz africana como para os adeptos infantis. Outros autores também são utilizados na fundamentação crítica do artigo.

\section{1. "LUMBIÁ": O MENINO DIVINO}

O livro de contos Olhos d'água reúne 15 contos que narram a vida de jovens, de adultos, e de negros e negras. Heloísa Tolles Gomes, no prefácio da obra, diz que sem sentimentalismos facilitadores, embora incorporados à tessitura poética da fiç̧ão, os textos apresentam uma significativa galeria de mulheres de muitas faces. Há, também, homens, amantes e crianças, todos evocados em seus vínculos e dilemas sociais, sexuais e existenciais, numa pluralidade e vulnerabilidade que constituem a condição humana, pontua. (GOMES, 2016)

Conceição Evaristo, no conto "Lumbiá", utiliza, por meio da escrevivência, a escrita de um corpo, de uma condição, de uma experiência negra no Brasil: o procedimento de brutalidade poética literária.

Oliveira (2009), no artigo "Escrevivências: rastros biográficos em Becos da memória, de Conceição Evaristo", explica os três elementos formadores do conceito de escrita da autora: corpo, condição e experiência. O primeiro refere-se à dimensão subjetiva do existir negro, arquivado na pele e na luta constante por 
afirmação e reversão de estereótipos: "lê-se o passado e a tradição contrabandeando-os, saqueando-os. A representação do corpo funciona como ato sintomático de resistência e arquivo de impressões que a vida confere." (OLIVEIRA, 2009, p. 88). O segundo volta-se para "um processo enunciativo fraterno e compreensivo com as várias personagens que povoam a obra"; uma espécie de "memória coletiva, já que o processo de identificação entre os personagens e a autora é latente." (OLIVEIRA, 2009, p. 88). O terceiro elemento "funciona tanto como recurso estético quanto de construção retórica, a fim de atribuir credibilidade e persuasão à narrativa." (OLIVEIRA, 2009, p. 88). Trata-se, pois, a escrevivência, de uma escrita da vivência da qual a escritora está consciente.

Ao dizer que trabalha com a arte da palavra articulada, Evaristo $(2017)^{2}$ explica que pode relatar morte de crianças e fazer isso de tal maneira sem deixar de ter muito cuidado com a "arrumação das palavras" na frase dando ritmo e contribuindo para dar beleza ao texto.

No conto em análise, num contexto em que mãe, filhos e amigos são pobres e, por isso, sofrem pela condição social, percebemos o arranjo linguístico no texto que, de certa forma, não mascara a miséria das personagens, mas suaviza a dureza da situação para o leitor, que é inserido nessa carência financeiro-social por meio desta poética evaristiana. Amenizar, contudo, não significa deixar de fazer denúncia e reflexão crítica.

Já se é sabido, como pontua Cuti (2010) em Literatura Negro-brasileira, que a literatura - negra - é uma ferramenta de militância e de construção identitária; trata-se de uma resistência contra o racismo e o preconceito racial, e é um instrumento não apenas para reagir e resistir às práticas de intolerância, mas também um elemento de empoderamento por inserir escritores negros e negras e a cultura afro-brasileira no campo da Literatura: o negro e a negra tornam-se protagonistas da própria história.

Conceição Evaristo, desta forma, narra a cultura e a sociedade das quais faz parte por meio do jogo linguístico-literário no conto "Lumbiá". Tal recurso é notado pelo duplo, pela ambiguidade e também pela junção e pelo imbricamento da cultura cristã com a afro-brasileira. Nesse sentido, a narrativa permite-nos pensar no relato do conto proposto por Piglia (2004), em Formas breves, ao discutir o caráter duplo dessa forma de prosa. Conforme o crítico, a forma clássica do conto está condensada no núcleo desse relato fictício e não escrito. No conto, explica o autor, a intriga se oferece como um paradoxo, o que resulta no caráter duplo desse tipo de narrativa: um conto sempre conta duas histórias.

Em "Lumbiá", a história do primeiro plano seria o desejo de a criança visitar o presépio e ver de perto o Deus-menino na loja Casarão Iluminado, e o relato em segredo da história seria o trabalho infantil atrelado ao perigo dos grandes centros urbanos, sinalizado pelo atropelamento de carro sofrido pela criança no centro da cidade, e às questões de gênero e raça.

Saiu [Lumbiá] da loja levando o Deus-menino. O segurança voltou. Tentou agarrar Lumbiá. 0 menino escorregou ágil, pulando na rua. 0 sinal! O carro! Lumbiá! Pivete! Criança! Erê, Jesus Menino. Amassados, massacrados, quebrados! Deus-menino, Lumbiá morreu! (EVARISTO, 2016, p. 85-86) 
Evaristo ressalta a arte de contista sinalizada em saber cifrar, literariamente, a história 2 nos interstícios da história 1. Para Piglia (2004), um relato visível esconde um relato secreto, narrado de modo elíptico e fragmentário. Assim, a surpresa é uma consequência da imersão do final da história secreta na superfície, o que surpreende o leitor. As duas histórias são contadas de modo distinto, uma vez que trabalhar com duas histórias (superfície do relato 1 e imersa do relato 2) quer dizer trabalhar com dois sistemas diferentes de causalidade.

A troca do salgado (amendoim) pelo doce (chiclete) e pelas flores é um índice da duplicidade no conto evaristiano aqui em análise. A narradora, desde as primeiras linhas, nos dá índices do perfil da personagem-protagonista do conto:

Lumbiá trocou rapidamente a lata de amendoim pela caixa de chicletes com a irmã Beba. Fazia um bom tempo que estava andando para lá e para cá, e não havia conseguido vender nada. Quem sabe teria mais sorte se oferecesse chicletes? E se não desse certo também, procuraria o colega Gunga. Juntos poderiam vender flores. A mãe não gostava daquela espécie de mercadoria. Dizia que flor encalhada era prejuízo certo. Sempre amanheciam murchas. Amendoim e chicletes não. Lumbiá gostava da florida mercadoria em seus braços. (EVARISTO, 2016, p. 81, grifos nossos)

Vemos a preferência de Lumbiá pelo adocicado do chiclete (paladar), pelo viçoso das flores (visão), marcada na ductibilidade e na maleabilidade da troca da lata pela caixa (tato). 0 duplo é visto aqui não como binário ou excludente, uma vez que a personagem protagonista possui o saber internacionalizado e "ancestralizado", como veremos.

Nesse sentido, no que se refere ao entendimento de binarismo sexo/gênero, tais questões não cabem mais:

A sociedade segue outro ritmo e precisa de conceitos mais inovadores para dar conta da demanda. Não se pode mais pensar, por exemplo, o sexo como dual, uma vez que, ao sairmos à rua, não vemos mais homens e mulheres, mas pessoas com possibilidade diversas. (NIGRO \& CHATAGNIER, 2018, p. 35, grifos nossos)

Lumbiá, ciente dessas "possibilidades diversas" não binárias, possui o próprio estilo de vendas; ao observar casais, sabe o momento eficaz para "empurrar o produto":

Feliz, Lumbiá e o amigo Gunga depois riam do beijo babado do homem e da mulher. Ele sabia também que não era só homem e mulher que se beijavam. Havia casais, em que a dupla era formada por semelhantes. Homem com homem. Mulher com mulher. Esses casais não se beijavam em público. Às vezes faziam um carinho rápido nas mãos do outro. [...] Lumbiá gostava muito de aproximar dos casais semelhantes. Gostava da troca carinhosa que ele às vezes assistia entre os pares. (EVARISTO, 2016, p. 82, grifos nossos)

A personagem não se aproxima desses "outros casais" para apenas vender o produto, mas, sim, porque respeita e aceita "os outros modos" de carinho entre os semelhantes, os quais driblam a sociedade preconceituosa e intolerante. Lumbiá menino é dócil e gosta de flores, predicados muitas vezes atrelado ao 
feminino na sociedade brasileira. A mãe da personagem, menos "romântica", por outro lado, não prefere a flor como mercadoria. Mas deixaria de ser feminina e se tornaria mais masculina por isso?

Ora, "a masculinidade está ligada a uma ideia socialmente constituída de que o homem precisa seguir determinadas tendências para justificar ou confirmar seu papel". Vale observar que as questões atreladas ao gênero, à masculinidade e à feminilidade na literatura brasileira são feitas, geralmente, por escritoras e pesquisadoras. (NIGRO \& CHATAGNIER, p. 42, 2018)

Os pontos de caráter duplo do conto podem ser notados no gênero literário, pois a escrevivência evaristiana em sua "arrumação de palavras" torna sobremaneira tênue as fronteiras entre prosa e poema.

Vejamos: "o beijo era depositado nas mãos, que escorregavam levemente na direção da palma da outra pessoa, ou substituindo pela leveza de uma flor-sorriso que se abria na intenção de um lábio a outro." (EVARISTO, 2016, p. 82-83, grifos nossos). Há, no fragmento supracitado, a coerência entre o modo de descrever o carinho feito pelos amantes semelhantes e a linguagem figurada. A "arrumação das palavras" evaristiana oblitera o sentido, mas o preenche de conteúdo poético.

Em "em meio às verdades-mentiras que tinha inventado, Lumbiá ia se descobrindo realmente triste, tão triste, profundamente magoado, atormentado em seu peito-coração menino" (EVARISTO, 2016, p. 83), as linguodentais oclusivas $/ \mathrm{t} / \mathrm{e} / \mathrm{d} /$ e as nasais $/ \mathrm{m} /, \mathrm{n} /$, respectivamente, sugerem as verdades e as mentiras amalgamadas no sentimento da personagem. As repetições em /ado/, /do/ e /da/, por sua vez, figuram as batidas do "peito-coração" de Lumbiá.

O nome motivado do amigo da protagonista salienta a poética de Evaristo, pois "Gunga", parceiro de vendas, é palavra de origem do grupo etnolinguístico banto: nome usado para denominar o berimbau-mestre da capoeira, aquele que dita o ritmo e dá início ao jogo; é sempre tocado pelo mestre ou capoeirista mais antigo do grupo (BATISTA, 2019). Lumbiá e Gunga, levando-se em consideração a cultura da capoeira e a semântico-linguística da palavra banto, estão juntos como o ritmo do berimbau para a realização da capoeira. Lumbiá, assim como o "Erê" referência que também será analisada neste artigo -, precisa do auxílio de "um mais velho", sinalizado no conto pelo amigo Gunga.

Ao inserir a cultura banto em sua poética, Conceição Evaristo nos oportuniza o conjunto rico e diversificado, o qual compreende distintos toques e batuques, num xirê de reflexões, tema, aliás, do presente dossiê.

Nei Lopes $(2008$, p. 9) ressalta a negação da importância cultural do segmento banto na formação brasileira, "apesar de sua relevância, pela anterioridade de sua presença e pelo número vultoso de sua entrada nos portos brasileiros, por mais de 300 anos, além de sua dispersão forçada por quase todo o território nacional [...]". Segundo o autor, essa omissão repercutiu no inconsciente nacional porque as ideias sobre uma suposta inferioridade foram formuladas, a partir do século XIX, por escritores tidos, então, como "luminares" da pesquisa científica, tais como Silvio Romero (1953, p. 132), em História da Literatura Brasileira, ao dizer que os negros, na formação brasileira, "são gentes [banto] ainda no período do fetichismo, brutais, submissas e robustas, as mais próprias para os árduos trabalhos de nossa lavoura rudimentar". 
Nina Rodrigues (1977, p. 20), em Os africanos no Brasil, assim como Romero, desqualifica a cultura banto, ao dizer que:

[...] no entanto, por mais avultada que tivesse sido a importância de negros da África Austral, do vasto grupo étnico dos negros de língua tu ou banto - e o seu número foi colossal -, a verdade é que nenhuma vantagem numérica conseguiu levar à dos negros sudaneses, aos quais, além disso, cabe inconteste a primazia em todos os feitos em que, da parte do negro, houve na nossa história uma afirmação da sua ação ou dos seus sentimentos de raça (grifos nossos).

Lopes (2008) também cita Afrânio Peixoto (1980, p. 281) do Breviário da Bahia: a preferência de todo "[...] o Brasil, exceto a Bahia, por Angola, é que embora mais feios, menos cultos, eram mais dóceis e obedientes ao trabalho. Muito afeiçoáveis ao cativeiro, ótimos criados, mas muito estúpidos, diz Taunay". Vale destacar que, entre os diversos estados bantos, sobressaiu-se um grande reino, o reino do Congo, que dominava grande parte dos atuais países Congo e Angola.

Além de Romero (1953), Rodrigues (1977) e Peixoto (1980), Lopes (2008) também cita Oliveira Vianna do Raça e assimilação (1959, p. 202), depois afirmar que "os negros puros, vivendo nas florestas do Congo ou da Angola, nunca criaram civilização alguma".

Percebemos, como aponta Lopes (2008, p. 94), a inferiorização dos bantos, em relação aos povos da África ocidental, apregoada "pelos eruditos do racismo científico". Entretanto, o autor cita, a partir dos estudos de Édison Carneiro (1981), Religiões negras, Negros bantos, a contribuição de Artur Ramos (1988 [1937]), em O negro brasileiro: etnografia religiosa e psicanálise, que, ao que parece, foi o primeiro pesquisador a notar a importância dos bantos para a cultura brasileira. Lopes (2008, p. 191) observa que, em relação aos sudaneses, a cultura banto foi, por muito tempo, considerada frágil, "sem estrutura, um amontoado de crendices e superstições, com suas bases emprestadas à teogonia nagô e facilmente engolidas pelo catolicismo".

Evaristo, ao contrário, transforma o instrumento de origem banto em nome próprio no discurso literário e permite que adentremos ao significado deste atrelado à capoeira. Feitas essas considerações, passemos para a questão da "Brutalidade poética" associada à referência do Erê da cultura afro-brasileira.

\section{BRUTALIDADE POÉTICA: O DEUS-MENINO-ERÊ}

Conceição Evaristo $(2017)^{3}$, ao comentar sobre o conto "Lumbiá", diz que queria incorporar, nessa estética literária negra, os elementos afro-brasileiros e, por isso, trouxe a figura do "Erê" para a narrativa.

Na cultura afro-brasileira, "erê", palavra de origem iorubá, conforme Beniste (2014), significa brincar, favor, fazer boa ação. No candomblé, é uma divindade infantil particular de cada adepto do culto e está atrelado ao orixá de cada um. Os erês auxiliam na comunicação entre os demais adeptos e o orixá a este associado.

Freitas (2019, p. 3) no artigo "Doces de Crianças: sobre comida e ritual em giras de ibejadas", explica uma distinção que Ihe fora apontada por adeptos do 
candomblé e da umbanda; os erês "[...] seriam as entidades infantis do candomblé e se distinguem dos orixás não só pelo comportamento de criança, mas pela fala; são os erês quem dão os recados, já que orixás não falam", já a ibejada está entre outras divindades do panteão umbandista.

Oliveira e Almirante (2017), em "Criança, terreiro e aprendizagem: um olhar sobre a infância no candomblé", explicam que os erês configuram-se como "atores" nos processos não formais de aprendizagem e ganham espaço na dimensão lúdica como elemento central na prática educativa das crianças do terreiro: "as crianças de candomblé, ainda que bastante invisibilizadas pela literatura que aborda as religiões afro-brasileiras, são sujeitos ativos, agenciadores e produtores de cultura" (OLIVEIRA; ALMIRANTE, 2017, p. 294).

Os autores demonstram como os processos de aprendizagem ditos não tradicionais das crianças (espirituais e não) podem ser articulados de modo sobremaneira complexos, e destacam o papel ativo das crianças na vida social do terreiro, indicando também a ludicidade como uma forma de subversão das hierarquias e de criação. (OLIVEIRA; ALMIRANTE, 2017)

Esses traços podem ser percebidos no protagonista do conto de Conceição Evaristo por meio do apreço pelo doce do chiclete, pelo viçoso das flores, pela simpatia e pela tolerância aos casais iguais e semelhantes e, principalmente, pelo presépio:

\footnotetext{
Só havia uma coisa que o menino gostava no Natal. Um único signo: o presépio com a imagem de Deus-menino. Todos os anos, desde pequeno, em suas andanças pela cidade com a mãe e mais tarde sozinho, buscava de loja em loja, de igreja em igreja, a cena natalina. Gostava da pobreza de todos, parecia a sua. Da imagem-mulher que era a mãe, da imagem-homem que era o pai. A casinha simples e a caminha de palha do Deus-menino, pobre, só faltava ser negro como ele. Lumbiá ficava extasiado olhando o presépio, buscando e encontrando o Deus-menino (EVARISTO, 2016, p. 83-84, grifos nossos).
}

O sentido mágico e sublime do Natal encanta e emociona Lumbiá que prefere os gestos nobres e simbólicos do presépio ao "pirotécnico espetáculo", ao "Papai Noel gordo e feliz das vitrines", aos "pinheiros iluminados e coloridos", aos "presentes expostos embrulhados e vazios". O protagonista desejava ver o maior, o mais bonito e comentado presépio da cidade montado na loja Casarão lluminado; precisava, entretanto, ir acompanhado e "para ele era quase impossível esperar pelo dia em que a mãe pudesse levá-lo, acompanhá-lo até lá. (EVARISTO, 2016, p. 84). O amigo Gunga, Beba e a irmã Beta tentaram sem sucesso, mas tentaram ajudar Lumbiá nesse gesto fraterno e de solidariedade comum às práticas dos erês nos terreiros.

Cabem neste momento as palavras de Evaristo no que se refere à escrita. Para a autora, a sua competência literária parte muito da escrevivência, da observação, do espaço em que viveu e vive, das pessoas que a "contaminaram" a ponto de virarem personagens: um espaço social ou que parte de uma ficcionalização que não é o meu campo. E aqui não tem nenhum julgamento de valor. O que eu 
quero afirmar aqui é o lugar da diferença, da concepção dos meus textos. Eu estou concebendo os meus textos - eu falo muito isso - a partir da minha condição de mulher negra. ${ }^{4}$

Ainda de acordo com a fala da escritora, citando Leonardo Boff, "cada um lê com os olhos que tem. E interpreta a partir de onde os pés pisam. Todo ponto de vista é a vista de um ponto":

A minha concepção, o meu trabalho de Literatura, o meu imaginário, a minha ficcionalização, nascem a partir do espaço onde meus pés estão fincados. E meus pés estão fincados no lugar de mulher na sociedade brasileira, no lugar de mulher negra na sociedade brasileira: a partir de minha história pessoal, foi uma mulher que nasceu e se criou numa favela, vem de situação subalterna e hoje faz isso, isso, isso e aquilo (grifos nossos).

A escrita dessa vivência - escrevivência - revela-se não só na necessidade de Lumbiá, da irmã e dos amigos Gunga e Beba em trabalhar nas ruas vendendo mercadorias, mas também na impossibilidade da mãe em levar o filho para ver o presépio na loja do centro da cidade. Diante disso, o menino entra escondido e apressado na loja para ver o presépio:

Lá estava o Deus-menino de braços abertos. Nu, pobre, vazio e friorento como ele. Nem as luzes da loja, nem as falsas estrelas conseguiam esconder a sua pobreza e solidão. Lumbiá olhava. De braços abertos, o Deus-menino pedia por ele. Erê queria sair dali. Estava nu, sentia frio. Lumbiá tocou na imagem, à sua semelhança. Deus-menino, Deus-menino! (EVARISTO, 2016, p. 85, grifos nossos).

Como já sinalizado, o comportamento da prosa narrativa aproxima-se do procedimento particular do poema, e a poesia se faz presente pela ambiguidade, pela junção entre Lumbiá e o Deus-menino, e pelas repetições. A "pobreza" e a "solidão" é do Deus-menino ou de Lumbiá? Quem quer sair dali? Erê Deus-menino ou Erê Lumbiá? Há, evidentemente, a conexão entre as imagens de Jesus-cristãocriança com a simbologia do Erê afro-iorubá-brasileiro na reciprocidade do amor e do fazer a boa ação.

O conceito de negritice, dada à escrita de Evaristo, é o estabelecimento do apreço a valores tanto internos quanto externos à própria cultura (negra-africana) e, por isso, assume-se a identidade catalista, híbrida. O termo é a união da negrice e da negritude, fundindo-as. Assim, conjugam-se os aspectos positivos da negritude e as configurações negativas da negrice, pontua Martins (2003). Na negritice, ocorre a superação das polaridades em que o "pai ocidental" (negrice) e o "pai africano" (negritude) se veem encurralados; nela, isolamentos culturais, raciais e nacionais podem - e devem - ser superados e desafiados, pontua Martins (2010).

Por meio da inserção do Erê, Evaristo faz emergir o sofrimento do povo negro, a história que se quer esconder e ocultar, mas que se eleva por meio da literatura, da "brutalidade poética" e, portanto, da escrevivência. Como pontua a Evaristo $(2017)^{5}$, "a nossa escrevivência não pode ser lida como história de ninar os da casa-grande, e sim para incomodá-los em seus sonos injustos". 
Ora, o texto de Conceição Evaristo parte do microcosmo, da vida particular das personagens, para avançar para o macrocosmo, o geral, a situação de negras (e negros), a subalternidade, o enfrentamento diário deste grupo que, ainda, sofre com o racismo, com o preconceito e com a discriminação étnico-racial e de gênero. Ainda conforme a autora:

Quando mulheres do povo como Carolina, como minha mãe, como eu também, nos dispomos a escrever, eu acho que a gente está rompendo com o lugar que normalmente nos é reservado. A mulher negra, ela pode cantar, ela pode dançar, ela pode cozinhar, ela pode se prostituir, mas escrever, não, escrever é alguma coisa... é um exercício que a elite julga que só ela tem esse direito. Escrever e ser reconhecido como um escritor ou como escritora, aí é um privilégio da elite (EVARISTO, 2010) ${ }^{6}$.

Evaristo (2019) ${ }^{7}$ explica que inserir a vivência do povo negro não apenas na prosa, mas também no poema "é sempre uma provocação mesmo; é para marcar um outro lugar de escrita; não é inocente. Meu projeto de escrita é a partir realmente de minha vivência".

O desfecho do conto, porém, por meio da brutalidade poética, elimina as possibilidades de manutenção da felicidade de Lumbiá que pega o Deus-menino nos braços e sai correndo da loja:

Saiu [Lumbiá] da loja levando o Deus-menino. O segurança voltou. Tentou agarrar Lumbiá. O menino escorregou ágil, pulando na rua.

O sinal! O carro! Lumbiá! Pivete! Criança! Erê, Jesus Menino. Amassados, massacrados, quebrados! Deus-menino, Lumbiá morreu! (EVARISTO, 2016, p. 85-86).

A justaposição das frases nominais, compostas por sintagmas nominais e adjetivos terminados em /ados/, figurativiza e constrói a sequência dos fatos do atropelamento, recurso linguístico literário que reforça a união de brutalidade com poética.

Ao desfecho do conto "Lumbiá", é possível trazer os "pontos de vistas de onde os pés pisam" em que Evaristo ${ }^{8}$ ressalva que o dito "todo mundo que se esforça", "todo mundo que trabalha consegue" é uma falácia. Para a autora, isso é uma mentira. Lumbiá vendia produtos nas ruas para ajudar no sustento familiar, mas não conseguiu a tão sonhada ascensão de classe social; as oportunidades mínimas foram findadas no atropelamento quando sai correndo com o Deus-menino nos braços. Portanto, por mais que a personagem protagonista tenha se esforçado na venda de flores e amendoim a fim de ajudar no sustento familiar, não houve a mudança socioeconômica, uma vez que, com a morte, Lumbiá morre e com ele o sonho de ascensão social.

Desse modo, a personagem é como muita gente que Evaristo conhece: "eu conheço muita gente que trabalha, que se esforça e chega num dado limite que as pessoas já não aguentam mais". A autora, quando the dizem que "conseguiu", destaca que foi preciso chegar aos 70 anos para "conseguir". Segundo Evaristo, se a história dos afro-brasileiros como Lumbiá fosse diferente, talvez teriam (os negros) outro patamar dentro da sociedade brasileira: "histórias como a minha apenas confirmam uma exceção dentro da regra", completa. 
Analisar o conto "Lumbiá" da premiada obra Olhos d'água, levando-se como fator teórico-metodológico a perspectiva de escrita e de literatura negra da própria autora Conceição Evaristo, permite-nos que reflitamos sobre o lugar da literatura feita por negros e negras sobre si mesmos. Conceição Evaristo, dessa forma, atreve-se, consciente de sua historicidade, a exercer este direito de escrever, embora a branquitude julgue que mulheres negras (e negros) não possam.

Ao unir os conteúdos culturais Deus-menino-cristão-erê, a autora se mostra consciente de que é preciso valorizar a cultura africana, percebida aqui pela negritude, sem desconsiderar a ocidental, presente na negrice; tal junção, portanto, resulta na negritice (MARTINS, 2010).

O texto deve ser redigido em fonte Calibre, tamanho da letra 11, espaçamento simples, entre linhas e parágrafos e espaços duplos entre partes do texto. As citações no corpo do texto devem seguir o sistema autor-data (BOSI, 1998, p. 15) e as referências devem seguir as normas 6023 da ABNT. Subtítulos, se houver, devem aparecer numerados (exceto Introdução, Conclusão e Referências), sem adentramento, em negrito, em maiúscula (caixa alta). Os artigos e ensaios devem conter no mínimo 10 e no máximo 20 páginas e as resenhas no mínimo 5 e no máximo 7 páginas.

\section{À GUISA DE CONCLUSÃO}

Como já apontado neste artigo, não é fácil chegar onde a autora chegou mesmo aos 70 anos de idade e trazendo conteúdos que por muito tempo foi subalternizado pelos estudos acadêmicos e pela sociedade. Quantas mulheres, quantos homens, negras e negros romperam com a barreira do racismo, do preconceito e da exclusão de gênero, de raça e de classe e se constituíram autoridades de saber crítico e literário? A Literatura Brasileira é majoritariamente feita por homens, brancos, ricos e heterossexuais (DALCASTAGNÉ, 2008). Quais oportunidades são dadas para pesquisadores que acreditam que é possível fazer "um xirê de pesquisas" em que a cultura dos terreiros podem ser pensadas na linguagem literárias e nas demais áreas do conhecimento?

O busto que homenageia a Mãe de Santo Gilda, localizado no Parque do Abaeté, no bairro de Itapuã, em Salvador no estado da Bahia, foi vandalizado no dia 15 de julho de 2020. De acordo com a Polícia Militar, o suspeito foi levado delegacia. No ano de 2016, o monumento da lalorixá também foi alvo de vandalismo e precisou ser reformado, de acordo com a reportagem da $\mathrm{G} 1^{9}$.

Um terreiro de Candomblé também foi alvo de vandalismo e de intolerância religiosa em1으 de julho de 2020, em Colombo, na região metropolitana de Curitiba no estado do Paraná. A casa teve a fachada pichada com a frase "Deus é maior", e os vândalos jogaram uma bíblia e uma garrafa pet com mensagens de ódio: "seu lugar é na a senzala, escravo do diabo", "o sangue de Jesus tem poder", "pecador, vai embora", etc., conforme reportagem da Tribuna $^{10}$.

O conto analisado possibilitou-nos, por outro lado, trazer para os estudos literários a reflexão sobre a presença da cultura dos iorubás, marcada pelo "erê" que, como apontado, teceu relações com o Deus-menino da cultura cristã, e da cultura do grupo etnolinguístico banto, inserida por meio do instrumento gunga que se torna nome próprio da personagem Lumbiá. 
Segundo Ford (1999), em O Herói com rosto africano - Mitos da África, a literatura (brasileira) não recebe bem os mitos africanos, e os mitologistas ocidentais, dentre os quais Joseph Campbell, referem-se, quando se voltam a estas narrativas, com zombaria, rebaixando as contribuições dos africanos ao nível das lendas populares julgadas inferiores.

Conforme Ford (1999, p. 11), os mitos "são histórias que contém símbolos universalmente reconhecíveis com significação psicológica e espiritual”. Ciente dessa idiossincrasia, Conceição Evaristo une culturas distintas num texto narrativo que se comporta, por vezes, como poema, e nos relata a história de meninos e meninas negras subalternizadas por meio da personagem Lumbiá.

Souza (2018), ao se voltar para questionamentos acerca da subalternidade e da liberdade na obra Cloud Atlas, de David Mitchell (2004), chama-nos a atenção para o fato de que a luta de resistência dos subalternos perpassa reflexões sobre a liberdade. Apoiado em Bauman (2014), Souza aponta, por consequência, que a liberdade engloba conceitos relacionados ao desejo, uma vez que

[...] há a necessidade de o homem satisfazer desejos e necessidades. [...] a liberdade para Bauman, é conquistada na medida em que a capacidade de ação do sujeito permita a realização dos desejos, ou ainda que esses últimos sejam reduzidos. (SOUZA, 2018, p. 63).

Até que ponto, então, é coerente dizer que Lumbiá gozou de liberdade? De que modo seu desejo pôde, de fato, ser realizado mesmo que, pela astúcia, ele tenha conseguido entrar na loja Casarão Iluminado, visto o presépio de perto e, ainda, pego o Deus-menino nos braços? A personagem de Evaristo está inserida em um espaço em que as normas funcionam contra o seu desejo, impedindo possibilidades tanto de expressão como de existência. Conceição Evaristo, assim, problematiza e amplia o próprio discurso, ganhando mobilidade frente à literatura hegemônica eurocentrada por meio da escrevivência.

Ao inserir a cultura afro-brasileira em sua escrita, a escritora entra em consonância com a perspectiva de Grosfoguel (2008) sobre a necessidade de incluir críticos e culturas não europeias nos debates. 


\title{
"Lumbiá": The God-boy Erê of Conceição Evaristo
}

\begin{abstract}
This article analyzes the way in which the writer Conceição Evaristo inserts elements of the Yoruba and Bantu culture linked to the Judeo-Christian culture, gender and social class from the short story "Lumbiá", inserted in the work Olhos d'água. For this purpose, Martins' critical studies $(2003 ; 2010)$ on the terms blackness, blackness and blackness will be used; those of Freitas (2019) and Oliveira and Almirante (2017) on the entities of umbanda and candomblé erê; those of Cuti (2010) with regard to black literature, among other theorists and critics. The writing of this article is justified by the Dossier proposal "Society and religions of African origin: dialogues", in which it is possible to reflect the culture of the terreiro and the child divinity through literary language. In addition, the present text provides an opportunity to reflect on the culture of the Bantu and Yoruba peoples in contemporary Brazilian literature in a critical way, since, for a long time, these groups were disqualified and demonized. The article was part of the post-doctoral internship research (2018-2020) that investigated the presence of the Bantu and Yoruba myths in the poetry of Conceição Evaristo.
\end{abstract}

KEYWORDS: Conceição Evaristo. Banto-Yoruba culture. Black literature. Poetics. Subalternity. 
${ }^{1}$ Disponível em: https://www.geledes.org.br/30-livros-para-ler-mais-escritorasnegras-em-2019/. Acesso em 23 de julho de 2020.

${ }^{2}$ Em entrevista para a Revista Bravo. Publicada em 6 de novembro de 2017. Disponível em: https://www.youtube.com/watch?v=J3eUi1ffrQl. Acesso em setembro de 2019.

${ }^{3}$ Entrevista O ponto de partida da escrita - Ocupação Conceição Evaristo. Gravação realizada em março de 2017 no Rio de Janeiro/RJ pela Itaú Cultural. Disponível em: https://www.youtube.com/watch?v=3CWDQvX7rno. Acesso em julho de 2020.

${ }^{5}$ Texto disponível em: http://www.itaucultural.org.br/ocupacao/conceicaoevaristo/escrevivencia/. Acesso em julho de 2020.

6

EVARISTO, Conceição. Depoimento. Entrevista concedida a Bárbara Araújo Machado. Rio de Janeiro, 30 de setembro de 2010.

7 Ciclo de Seminários Mulheres nas Artes. Módulo II - Entrevista aberta com Conceição Evaristo. Acesso em julho de 2020.

${ }^{8}$ Ver nota 2.

9 Disponível IN: https://g1.globo.com/ba/bahia/noticia/2020/07/15/busto-demae-gilda-e-alvo-de-vandalismo-em-salvador-suspeito-foi-levado-paradelegacia.ghtml. Acesso em 23 de julho de 2020.

${ }^{10}$ Disponível IN: https://www.tribunapr.com.br/noticias/curitiba-regiao/terreirona-regiao-de-curitiba-sofre-ataque-racista-seu-lugar-e-na-senzala/. Acesso em 23 de julho de 2020.

\section{REFERÊNCIAS}

BATISTA, Mateus Schimith. A poética do ator e o encantamento na capoeira. Revista Latinoamericana de Estudios em Cultura y Sociedad. V. 5, edição especial, maio, p. 1-10, 2019.

BRASIL. Lei no 10.639 - 09 de janeiro de 2003. Brasília: Ministério de Educação, 2003.

Lei $n^{0} 11.645$ de 10 de março de 2008. Disponível em: http://www.planalto.gov.br/ccivil_03/_Ato20072010/2008/Lei/L11645.htm. Acesso em jul. 2020. 
CARNEIRO, Edison. Religiões negras: negros bantos. Rio de Janeiro: Civilização Brasileira, 1981.

CUTI. Literatura negro-brasileira. São Paulo: Selo Negro Edições, 2010.

BENISTE, José. Dicionário yorubá-português. Rio de Janeiro: Bertrand Brasil, 2014.

DALCASTAGNÉ, Regina. Homem, branco, rico e heterossexual. Entrevista feita por Paula Santos pelo Boletim número 1619, ano 34 de 04 de agosto de 2008. Disponível em: https://www.ufmg.br/boletim/bol1619/5.shtml. Acesso em jul. 2020.

EVARISTO, Conceição. Entrevista aberta com Conceição Evaristo ao Ciclo de Seminários Mulheres nas Artes. Módulo II. Publicado em 3 de julho de 2019. Disponível em: https://www.youtube.com/watch?v=yy6cTCYe8k4. Acesso em jul. 2020.

. A beleza ao criar. Entrevista concedida à Revista Bravo. Publicada em 6 de novembro de 2017. Disponível em: https://www.youtube.com/watch?v=J3eUi1ffrQI. Acesso em jul. 2020.

Escrevivência. Entrevista concedida ao Itaú Cultural em maio de 2017. Disponível em: http://www.itaucultural.org.br/ocupacao/conceicaoevaristo/escrevivencia/. Acesso em jul. 2020.

. O ponto de partida da escrita - Ocupação Conceição Evaristo. Entrevista concedida ao Itaú Cultural. Gravação realizada em março de 2017 no Rio de Janeiro/RJ. Disponível em: https://www.youtube.com/watch?v=3CWDQvX7rno. Acesso em jul. 2020.

. Olhos d'água. Rio de Janeiro: Pallas; Fundação Biblioteca Nacional, 2016.

. Depoimento. Entrevista concedida a Bárbara Araújo Machado.

Rio de Janeiro, 30 de setembro de 2010. Disponível em: https://www.encontro2012.historiaoral.org.br/resources/anais/3/134039319 9_ARQUIVO_TextocompletoENHO.pdf. Acesso em jul. 2020.

FORD, Clyde. O herói com rosto africano: mitos da África. Tradução de Carlos Mendes Rosa. São Paulo: Summus, 1999. 
FREITAS, Morena Barroso Martins de. Doces de crianças: sobre comida e ritual em giras de ibejadas. Dossiê Saberes e sabores. Revista Equatorial, Natal, v. 6, n. 11, p. 1-19, jul/dez 2019.

GOMES, HeloísaTolles. Prefácio da obra Olhos D’água. IN: EVARISTO, Conceição. Olhos d'água. Rio de Janeiro: Pallas; Fundação Biblioteca Nacional, 2016, p. 9-11.

GROSFOGUEL, Ramón. Para descolonizar os estudos de economia política e os estudos pós-coloniais: transmodernidade, pensamento de fronteira e colonialidade global. Revista Crítica de Ciências Sociais, Coimbra, n. 80, p. 115-147, 2008.

LOPES, Nei. Bantos, malês e identidade negra. Belo Horizonte: Autêntica, 2008 .

MARTINS, José Endoença. Negritice: Repetição e Revisão. In: MARTINS, José Endoença. O olho da cor: uma peça em três atos. Blumenau: Edição do Autor, 2003, p. 13-18.

Negrice, negritude, negritice: conceitos para a análise de identidades afrodescendentes nos romances $\mathrm{O}$ mundo se despedaça, de Chinua Achebe, e Chorai, pátria amada, de Alan Paton. Revista da Associação Brasileira de Pesquisadores/as Negros/as (ABPN), [S.1.], v. 1, n. 2, p. 195-216, out., 2010.

NIGRO, Cláudia Maria Ceneviva; CHATAGNIER, Juliane Camila. Da tradição à ruptura: representações do masculino na literatura brasileira. IN: TOLOMEI, Cristiane Navarrete; BENFATTI, Flávia Andrea Rodrigues. Gênero, raça e sexualidade na literatura. São Luís: Edufma, 2018, p. 3249.

OLIVEIRA, Amurabi; ALMIRANTE, Kleverton Arthur. Criança, terreiro e aprendizagem: um olhar sobre a infância no candomblé. Estudos de Religião, v. 31, n. 3, 273-297, 2017.

OLIVEIRA, Luiz Henrique Silva de. Escrevivências: rastros biográficos em Becos da memória, de Conceição Evaristo. Terra Roxa e Outras Terras. Revista de Estudos Literários, Volume 17-B, dez. 2009.

PEIXOTO, Afrânio. Breviário da Bahia. Rio de Janeiro: MEC, Cons. Fed. Cultura, 1980. 
PIGLIA, Ricardo. Formas breves. São Paulo: Cia. Das Letras, 2004.

RAMOS, Artur. O negro brasileiro: etnografia religiosa e psicanálise. Edição Fac-Similar. Rio de Janeiro/Recife, Civilização Brasileira, Fundação Joaquim Nabuco/Editora Massangana. (1988 [1937]).

RODRIGUES, Nina. Os africanos no Brasil. São Paulo: Nacional, 1977.

ROMERO, Sílvio. História da literatura brasileira. Rio de Janeiro: José Olympio, 1953.

SOUSA, Davi Silistino de. A subalternidade em Cloud Atlas, de David Mitchell. Dissertação de Mestrado. Universidade Estadual Paulista, São José do Rio Preto, 2018.

VIANNA, Oliveira. Raça e assimilação. 4 edição. Rio de Janeiro: José Olympio, 1959.

Recebido: 24 jul. 2020

Aprovado: 08 ago. 2020

DOI: $10.3895 /$ rl.v22n38.12830

Como citar: PASSOS, Leandro. "Lumbiá": O Deus-menino Erê, de Conceição Evaristo. R. Letras, Curitiba

v.22, n.38, p.52-67, set. 2020. Disponível em: <https://periodicos.utfpr.edu.br/rl>. Acesso em: XXX.

Direito autoral: Este artigo está licenciado sob os termos da Licença Creative Commons-Atribuição 4.0 Internacional.

\section{(c) (1)}

